\title{
A stainless-steel mortar, pestle and sleeve design for the efficient fragmentation of ancient bone
}

\author{
Agata T Gondek ${ }^{1}$, Sanne Boessenkool ${ }^{1} \&$ Bastiaan Star $^{1}$ \\ ${ }^{1}$ Centre for Ecological \& Evolutionary Synthesis (CEES), Department of Biosciences (IBV), University of Os/o \\ (UIO), Blindern, NO-0316 Oslo, Norway
}

BioTechniques 64:266-269 (June 2018) 10.2144/btn-2018-0008

Keywords: ancient DNA $\bullet$ bleach $\bullet$ bone $\bullet$ crushing $\bullet$ extraction $\bullet$ homogenize $\bullet$ pulverize $\bullet$ stainless steel

Different types of milling equipment - such as oscillating ball mills, freezer mills, mortar and pestle - can be used to fragment ancient bone prior to DNA extraction. However, each of these tools is associated with practical drawbacks. Here, we present the design for a stainless-steel mortar and pestle, with a removable sleeve to contain bone material. The tool is easy to clean, practical and its simplicity allows university workshops equipped with a lathe, boring tools and a milling machine to make these components at local expense. This design allows for the efficient fragmentation of ancient bone and improves sample throughput. This design is recommended as a useful, economical addition to existing laboratory equipment for the handling of ancient bone.

To improve the economy and throughput of research projects, laboratory protocols require periodic evaluation with an aim to reduce human handling time and/or increase accuracy or efficiency. Such evaluation is of particular importance in ancient DNA (aDNA) laboratories where laboratory time associated with minimizing contamination forms a significant cost. Here, we present a design for an easily cleaned, stainless steel mortar and pestle with a removable sleeve for fragmenting and pulverizing ancient bone, which is a fundamental procedure prior to DNA extraction [1]. Even though a broad range of laboratory mills, grinders and crushers such as rotor-, knife-, disc- or ballbased mills, mortar grinders, jaw crushers or drills are available, not all tools can be easily adapted to cleanroom standards. The most commonly used equipment and approaches in aDNA studies are grinding balls with shaking or freezer mills [2-8], but also mortar and pestle is used [9-11], or drills are used at low rotational velocity [12,13]. While these approaches are suitable, each method has practical disadvantages. For instance, bone fragmentation in oscillating ball or freezer mills occurs in closed beakers during a pre-set milling time. After this period, the containers are removed from the machine for visual inspection of the extent of fragmentation. This process leads to iterative tool (re)assembling to ensure complete milling and may result in over-processing of easily fragmented samples. Moreover, these mills require time-consuming cleaning routines and represent a significant capital investment. While mortar and pestle are significantly cheaper and more straightforward to clean, it can be difficult to control impact and to keep fragments contained within the mortar, leading to the scattering of bone material throughout the working area. In addition, some samples may simply be too hard to be processed this way. Finally, the low rotational velocity required for drills to avoid the burning of bone results in substantial handling time in order to obtain sufficient powder. The design presented here addresses several of the drawbacks mentioned above.

The design consists of three parts mortar, pestle and sleeve - that adhere closely together (Figure 1). The design is adapted from commercially available mortars that are used for the fragmentation of ores and minerals, for instance Impact Mortar and Pestle (cat. no 845/850 Chemplex ${ }^{\circledR}, \mathrm{FL}$, USA) or Plattner's mortar and pestle (cat. no. 6883L10, Thomas
Scientific, NJ, USA) with several modifications for the specific purpose of fragmenting ancient bone. First, we elongated the pestle to provide easy grip and prevent fine bone powder from reaching hand level while exiting the sleeve during repetitive grinding. Second, we elongated the sleeve to allow the pestle to remain in the sleeve to help contain the material. Third, we reduced the depth of the mortar chamber for easy access during cleaning. Fourth, we removed a 1-mm thick section over the entire length of the pestle. This allows the pestle to move more freely inside the mortar chamber and prevents the build-up of air-pressure. Initial tests of an earlier design without such section removed revealed that a tight fit of the pestle within the sleeve can result in the build-up of air-pressure with each downward move of the pestle. This pressure can then push fine bone powder through small seams between the mortar chamber and sleeve. Finally, each separate item (mortar, sleeve and pestle) is identified by an engraved number so that all pieces of a set can be kept together during handling.

All items have been constructed of stainless steel (AISI 316L) in the Instrument Workshop at the University of Oslo (Norway) using a lathe and boring tools. The mortar

We present an economical design of a stainless-steel mortar, pestle and sleeve for the efficient and controlled fragmentation of ancient bone. 


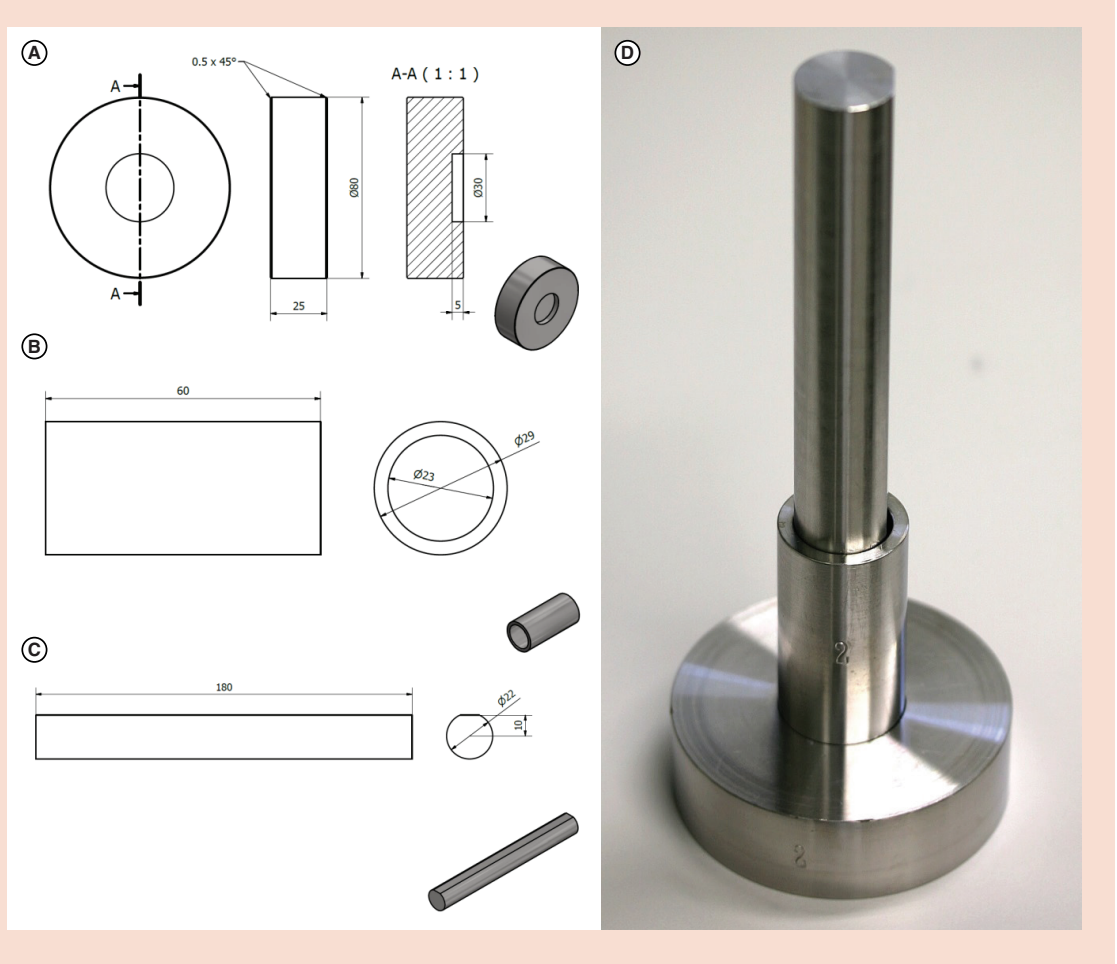

Figure 1. Design specifications. (A) Mortar, (B) sleeve and (C) pestle for the fragmentation of ancient bone. All measurements are in millimetres. Each item is made of stainless steel (AISI 316L). (D) Photo of the assembled tool set.

base is $25-\mathrm{mm}$ high with a diameter of $80 \mathrm{~mm}$, and the chamber has a depth of $5 \mathrm{~mm}$ with a diameter of $30 \mathrm{~mm}$ (Figure 1A). The sleeve has an outer diameter of $29 \mathrm{~mm}$, inner diameter of $23 \mathrm{~mm}$ and a height of $60 \mathrm{~mm}$ (Figure 1B). The pestle has a diameter of $22 \mathrm{~mm}$, a length of $180 \mathrm{~mm}$ and a 1-mm thick segment is removed from the transverse section over the entire length of the pestle (Figure 1C). All pieces are engraved with a respective set number (Figure 1D).
In our laboratory, the stainless-steel mortar, pestle and sleeve design compares favorably to an oscillating mixer mill (Table 1). The design is quicker to assemble and clean, the material withstands a harsh cleaning routine and is corrosion resistant. Moreover, during milling with the mortar, pestle and sleeve, it is easy to directly observe the progress of fragmentation. These features result in an improved sample throughput for a given number of working hours (Table 1). The design is capable of handling hard bones, including Atlantic walrus [14], and is sufficiently robust to be used in combination with a rubber hammer, with no risk of overheating. We find that the tool proved to be especially useful while handling petrous bone samples, whereby the lower density parts of the bone break off preferentially after initial impacts of the pestle, making it easy to isolate the dense section of the petrous bone, which contains the most endogenous DNA $[15,16]$, for further fragmentation. Finally, this design can be acquired at a fraction of the cost of an oscillating mill and beaker (Table 1).

In our experience, the three-piece stainless-steel mortar, pestle and sleeve is a versatile, economical and effective tool for fragmenting ancient bone. We have introduced specific modifications that are particularly useful for aDNA applications and find that the possibility to monitor the degree of bone pulverization while containing bone fragments within the sleeve provides a distinct advantage. The tool's simple design allows university workshops equipped with a lathe, boring tools and a milling machine to make these sets at local expense, which in Norway - is more economical compared with commercially available varieties designed for ores and minerals. Moreover, the capital investment is significantly less than oscillating mixer mills. We recommend this design as a useful, economical addition to existing laboratory equipment for the efficient handling of ancient bone.

\section{Author contributions}

BS \& ATG conceptualized the design. ATG designed the mortar, pestle and sleeve. ATG tested all designs. BS and SB provided

Table 1. Comparison of milling tools for the fragmentation of ancient bone.

\begin{tabular}{|c|c|c|c|c|}
\hline & & Zirconium beakers & Steel beakers & Mortar, pestle and sleeve \\
\hline Time (min) & Tool assembly & 2 & 2 & $<0.5$ \\
\hline & $\begin{array}{l}\text { Cleaning; one set (batch of } \\
\text { six sets) }\end{array}$ & $35(75)$ & $30(70)$ & $20(55)$ \\
\hline Cost (US\$) & Single tool set ${ }^{\dagger}$ & $\$ 2,683$ & $\$ 1,636$ & $\$ 186^{\ddagger}$ \\
\hline & Oscillating mixer mill ${ }^{\S}$ & $\$ 11,604$ & $\$ 11,604$ & $\mathrm{~N} / \mathrm{A}$ \\
\hline Throughput & & 12 & 12 & 18 \\
\hline Observation & & Requires (re)assembly & Requires (re)assembly & No (re)assembly \\
\hline Maximum b & & Hard & Medium & Hard \\
\hline UV resistan & & No & Yes & Yes \\
\hline $\begin{array}{l}\text { Estimates fo } \\
\text { fected by dif } \\
{ }^{\dagger} A \text { minimum } \\
\text { Retsch }{ }^{\text {mm }} 022 \\
{ }^{\ddagger} \text { The cost for } \\
{ }^{\S} \text { Retsch }{ }^{\text {Tm } 20}\end{array}$ & $\begin{array}{l}\text { are based on laboratory routine } \\
\text { tines, type of bone, exchange } \\
\text { is required for operating the os } \\
\text { includes material and labor. }\end{array}$ & $\begin{array}{l}\text { samples handled at the } \mathrm{aD} \\
\text { hipping and local labor cos } \\
\text { g mill. A single tool set co }\end{array}$ & y of the University of Oslo. & s are therefore approximate an \\
\hline
\end{tabular}


funding and consumables. BS \& ATG wrote the manuscript in collaboration with SB.

\section{Competing interests}

The authors declare no competing interests.

\section{Acknowledgements}

We thank Jan Kristiansen from the University of Oslo Instrumental Workshop for help with designing and manufacturing the mortar, pestle and sleeve.

\section{Financial \& compet- ing interests disclosure}

This work was supported by the Research Council of Norway grant 262777 to BS and 230821 to SB. The authors have no other relevant affiliations or financial involvement with any organization or entity with a financial interest in or financial conflict with the subject matter or materials discussed in the manuscript apart from those disclosed.

No writing assistance was utilized in the production of this manuscript.

\section{Open access}

This work is licensed under the Creative Commons Attribution 4.0 License. To view a copy of this license, visit http://creativecommons.org/licenses/by/4.0/

\section{References}

1. Morales Colón E, Hernández M, Candelario M, Meléndez M, Dawson Cruz T. Evaluation of a freezer mill for bone pulverization prior to DNA extraction: an improved workflow for STR analysis. J. Forensic Sci. 62(2), 530-535 (2018).

2. Rohland N, Hofreiter M. Ancient DNA extraction from bones and teeth. Nat. Protoc. 2, 1756 (2007).

3. Mitchell KJ, Llamas B, Soubrier J et al. Ancient DNA reveals elephant birds and kiwi are sister taxa and clarifies ratite bird evolution. Science 344, 898-900 (2014).

4. Boessenkool S, HanghØj K, Nistelberger HM et al. Combining bleach and mild pre-digestion improves ancient DNA recovery from bones. Mol. Ecol. Res. 17(4), 742-751 (2017).

5. Lazaridis I, Nadel D, Rollefson G et al. Genomic insights into the origin of farming in the ancient Near East. Nature 536, 419 (2016).

6. Palacio P, Berthonaud V, Guérin C et al. Genome data on the extinct Bison schoetensacki establish it as a sister species of the extant European bison (Bison bonasus). BMC Evol. Biol. 17(1), 48 (2017).

7. Star B, Boessenkool S, Gondek AT et al. Ancient DNA reveals the Arctic origin of Viking Age cod from Haithabu, Germany. Proc. Natl Acad. Sci. USA 114(34), 9152-9157 (2017). 8. Kennett DJ, Plog S, George RJ et al. Archaeogenomic evidence reveals prehistoric matrilineal dynasty. Nat. Commun. 8, 14115 (2017).

9. Knapp M, Clarke AC, Horsburgh KA, Matisoo-Smith EA. Setting the stage-building and working in an ancient DNA laboratory. Anal. Anat. 194(1), 3-6 (2012).

10.Fortes GG, GrandalD'anglade A, Kolbe B et al. Ancient DNA reveals differences in behaviour and sociality between brown bears and extinct cave bears. Mol. Ecol. 25(19), 4907-4918 (2016).

11. Matisoo-Smith EA, Gosling AL, Boocock J et al. A European mitochondrial haplotype identified in ancient Phoenician remains from Carthage, North Africa. PLoS ONE 11(5), e0155046 (2016).

12. Adler C, Haak W, Donlon D, Cooper A, Consortium G. Survival and recovery of DNA from ancient teeth and bones. J. Archaeol. Sci. 38(5), 956-964 (2011).

13. Sirak K, Novak M, Cheronet $\mathrm{O}$. A minimally invasive method

\section{The world's only aliquoting pipet controller}

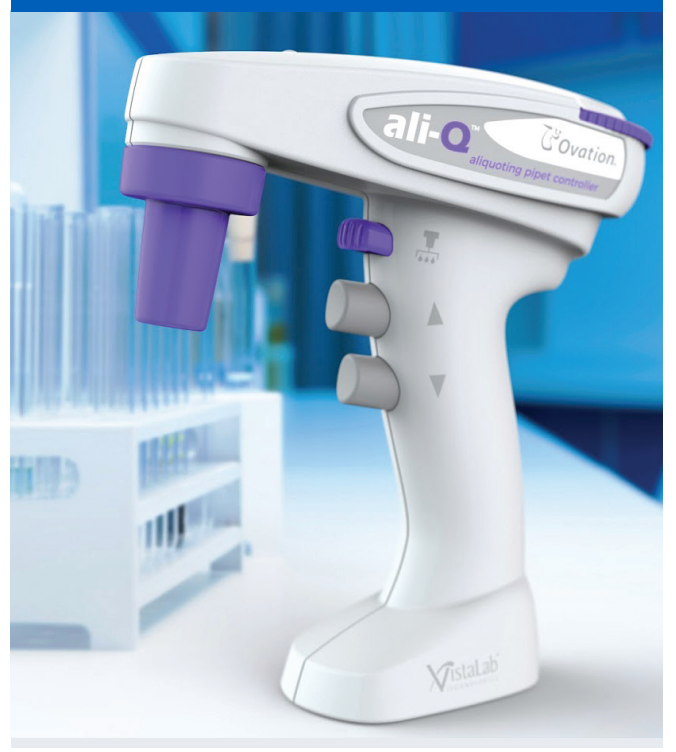

\section{One-button aliquoting}

Multidispense the same volume over and over again with high accuracy and precision, without having to "eyeball" the meniscus.

\section{Unlike any other pipetter}

ali-Q's innovative intelligent measuring system means:

- Accurate repeat pipetting with the push of one button.

- Use with serological pipets of any size or brand.

- Also aspirate and dispense as with standard pipet controllers/fillers.

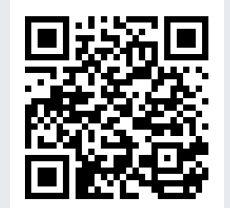

See the ali- $Q^{m}$ in action: vistalab.com/ali-q

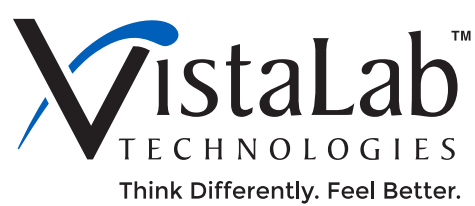

vistalab.com/ali-q • +1 914-244-6226 2

Geneva Road, Brewster NY 10509 
for sampling human petrous bones from the cranial base for ancient DNA analysis. BioTechniques 62(6), 283-289 (2017).

14. Star B, Barrett JH, Gondek AT, Boessenkool S Ancient DNA reveals the chronology of walrus ivory trade from Norse Greenland. bioRxiv doi:10.1101/289165 (2018)

15. Pinhasi R, Fernandes D, Sirak K et al. Optimal ancient DNA yields from the inner ear part of the human petrous bone. PLOS ONE 10(6), e0129102 (2015)
16. Hansen HB, Damgaard PB, Margaryan A et al. Comparing ancient DNA preservation in petrous bone and tooth cementum. PLOS ONE 12(1), e0170940 (2017).

Received: 15 February 2018; Accepted for publication: 25 April 2018

Address correspondence to: Bastiaan Star, Centre for Ecological \& Evolutionary Synthesis (CEES), Department of Biosciences (IBV), University of Oslo (UIO), Blindern, NO-0316 Oslo, Norway.

E-mail:bastiaan.star@ibv.uio.nol

To purchase reprints of this article, contact s.cavana@future-science.com

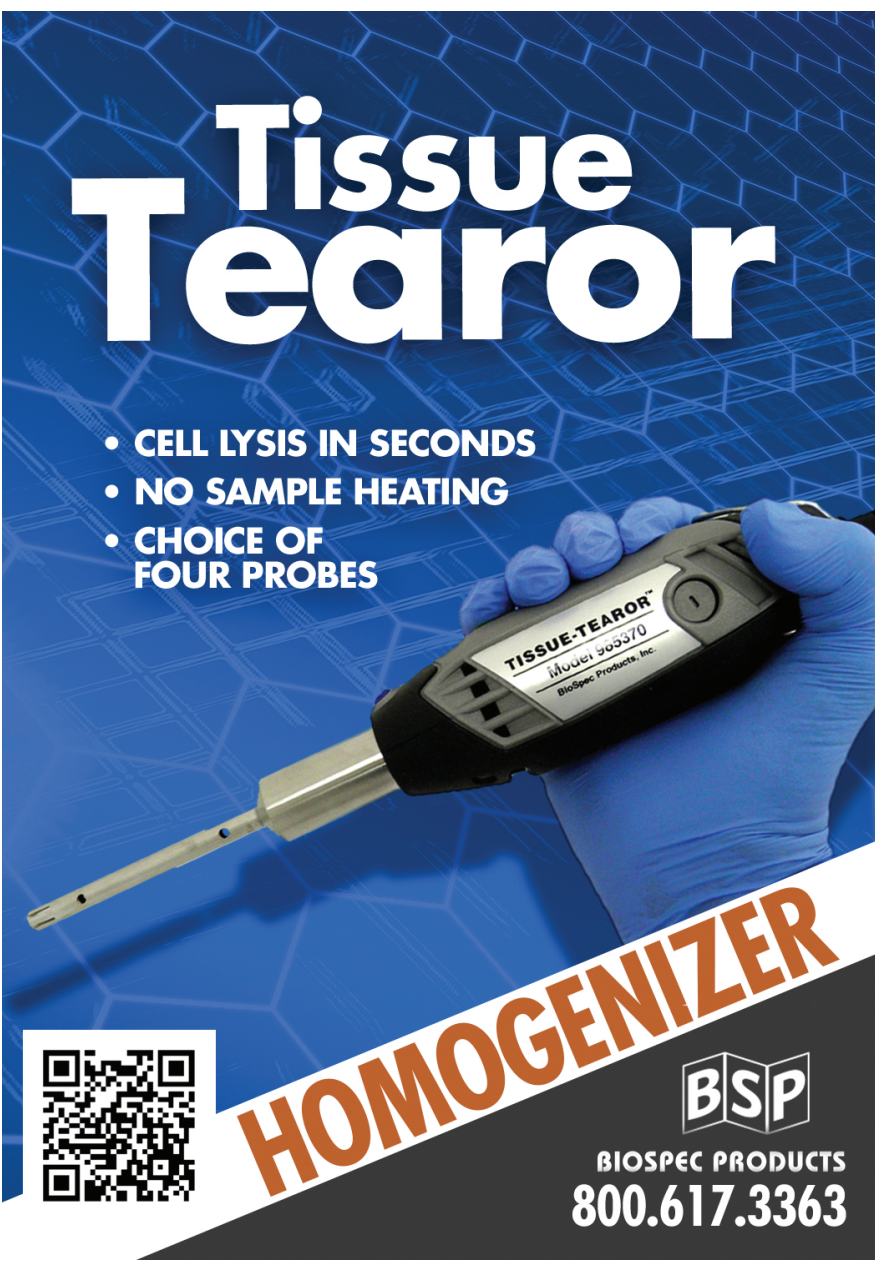

Avoid pipetting pain

\section{and increase productivity}
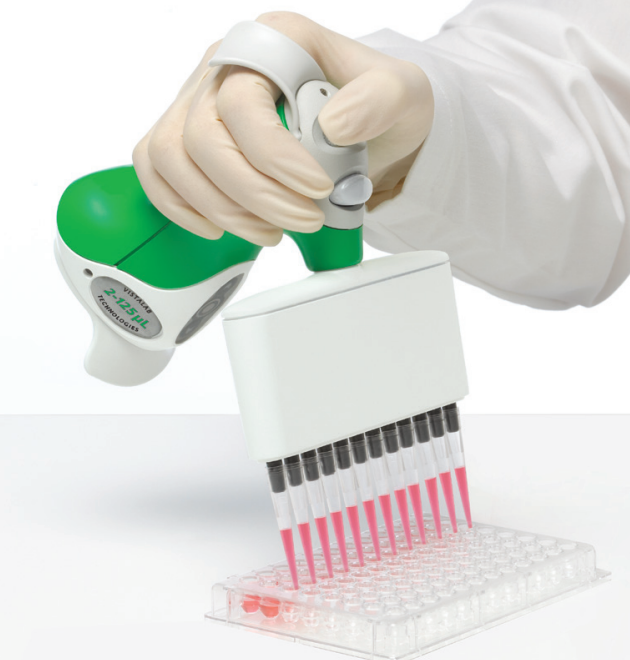

\section{Ovation ${ }^{\circledR}$ users love the patented ergonomic design}

"Ovation pipettes are very easy to use. My hands never get tired or hurt."

"Tips fit so well. They're easy to put on and easy to eject."

"Can't remember the last time I had a tip fall off."

\section{Only Ovation Multichannel} pipettes will give you:

- Uniform tip acquisition without "rocking" \& "pounding".

- Reliable, consistent filling across all channels.

- Better replicates for better statistical significance.

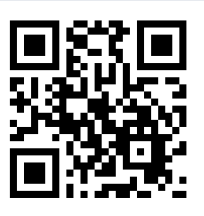

For more ergonomic info and a FREE 2-WEEK TRIAL

"They made the 2-week trial so easy!"

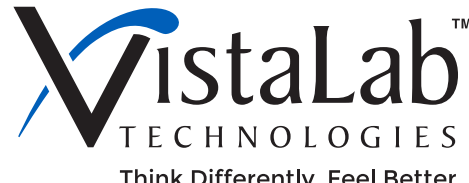

vistalab.com/ovation • +1 914-244-6226 2 Geneva Road, Brewster NY 10509 